\title{
A neurological and philosophical perspective on the design of environments and technology for older people with dementia
}

\author{
Maarten J. Verkerk, Joost van Hoof, Sil Aarts, Sylvia J.M.M. de Koning and \\ Johanna J. van der Plaats
}

\begin{abstract}
Purpose - Older people with dementia (OPD) have specific housing and technology-related needs, for which various design principles exist. A model for designing environments and its constituting items for people with dementia that has a firm foundation in neurology may help guide designers in making design choices. The paper aims to discuss these issues.

Design/methodology/approach - A general design model is presented consisting of three principles for $O P D$, namely designing for ageing people; designing for a favourable state and designing for beautiful moments. The neurosciences as a whole give shape to an eminent framework explaining the behaviour of $O P D$. One of the objectives of this paper is to translate the design principles into design specifications and to show that these specifications can be translated in a design.

Findings - Philosophical concepts are introduced which are required to understand design for OPD. Four case studies from Dutch nursing homes are presented that show how the theory of modal aspects of the philosopher Dooyeweerd can be used to map design specifications in a systematic way.

Research limitations/implications - These examples of design solutions illustrate the applicability of the model developed in this article. It emphasises the importance of the environment for supporting the daily life of $O P D$.

Originality/value - There is a need for a design model for OPD. The environment and technology should initiate positive behaviours and meaningful experiences. In this paper, a general model for the designing of environments for OPD was developed that has a firm foundation in neurology and behavioural sciences. This model consists of six distinct steps and each step can be investigated empirically. In other words, this model may lay the foundation for an evidence-based design.
\end{abstract}

Keywords Environment, Dementia, Technology, Philosophy, Design, Alzheimer

Paper type Research paper

\section{Introduction}

Worldwide, there is a sharp rise in the number of older people with dementia (OPD). In 2010, there were approximately 35 million OPD, and this number is expected to rise to 115 million in 2050 (Prince and Jackson, 2009). The increasing group of OPD poses challenges, including the development of technology and housing that fit their needs (Brawley, 1997; Day et al., 2000; Calkins, 2009; van Hoof et al., 2009; van Hoof, Kort, van Waarde and Blom, 2010; van Hoof and Verkerk, 2013; van Hoof et al., 2013; Marquardt et al., 2014; Charras et al., 2016; Kazak et al., 2017; Kenigsberg et al. , 2017). OPD cope with the same age-related health problems as other older people. For example, the sense of hearing, eyesight, and mobility (Ebersole et al., 2004; van Hoof, Kort, Duijnstee, Rutten and Hensen, 2010; Kenigsberg et al., 2015), are abilities that may deteriorate when growing old. Hence, the principles for designing for dementia ideally include principles that are applicable for the ageing population in general.
The authors affiliations can be found at the end of this article.

Received 5 November 2017 Revised 15 January 2018 Accepted 14 March 2018

(c) Maarten J. Verkerk, Joost van Hoof, Sil Aarts, Sylvia J.M.M. de Koning and Johanna J. van der Plaats. Published by Emerald Publishing Limited. This article is published under the Creative Commons Attribution (CC BY 4.0) licence. Anyone may reproduce, distribute, translate and create derivative works of this article (for both commercial and non-commercial purposes), subject to full attribution to the original publication and authors. The full terms of this licence may be seen at http://creativecommons.org/ licences/by/4.0/legalcode

Conflict of interest: the authors declare that there is no conflict of interest regarding the publication of this paper.

The Regional Attention and Action for Knowledge circulation (RAAK) scheme, which is managed by the Foundation Innovation Alliance (SIA - Stichting Innovatie Alliantie) with funding from the Dutch Ministry of Education, Culture and Science (OCW), is thanked for their financial support (SIA Project Number 2015-02-24M, Project SCHAT - Smart Care Homes and Assistive Technologies). 
The design principles for age-friendly technology and housing are described in various manuals (Fischer and Meuser, 2009; Feddersen and Ludtke, 2011).

OPD, however, are also confronted with specific physical, emotional, and cognitive limitations that are inherent to their condition. Various researchers proposed design principles specifically aimed at the declining abilities of OPD (Lawton and Nahemow, 1973; Pynoos et al., 1989; Marshall, 1998; Cohen and Weisman, 1991; Brawley, 1997; Marquardt et al., 2014; Hadjir et al., 2015). These researchers proposed the provision of clear and well-structured environments that can serve as a guide to behaviour, memory and reality orientation. Steeman et al. (2007) emphasised that we should support the remaining competences instead of focussing only on the skills that OPD are lost. The current design principles for technology and housing for OPD are based on their own experiences and those of their relatives and carers. These principles are not very specific and lack a firm foundation in neurology and behavioural sciences.

In the last decades, new insights were gained regarding the relationship between dementia, brain processes and human behaviour. OPD are decreasingly able to comprehend the environment around them and to plan their daily activities given their own cognitive abilities (Zuidema, 2008; van der Plaats, 2010). The contribution of the cognitive part of the brain to the execution of adequate behaviour diminishes gradually, and the emotional part takes over step by step (Woods, 2001). Behaviour merely becomes an emotional reaction to stimuli from the environment (Cools, 2012). It has been proposed that the purpose of a well-designed building, its interior and technologies for people with dementia should be aimed at evoking deliberate behaviour (de Koning, 2012).

The general objective of this paper is to support architects and designers to design a building, its interior and its technologies that match the needs and wishes of OPD based on knowledge of neurology and behavioural sciences. We have three specific aims:

1. to propose a general model for designing for OPD that has a firm foundation in neurology and behavioural sciences;

2. to identify principles for designing housing for OPD; and

3. to develop a methodology to translate design principles in design specifications.

This paper has the following structure. In section 2 the general model and the research methodology is presented. In Sections 3-8 the different steps of the model are described and discussed. The paper closes with conclusions.

\section{General model and research methodology}

Evidence-based design is the "holy grail" for designing products, technology and housing for OPD (Ulrich, 2006; van Hoof et al., 2015). In our view, the development of evidence-based designs requires models that explicitly relate neurological processes, behaviour, design principles and design. Each part of this model should be subjected to the cycle of hypothesis formulation and scientific testing.

Figure 1 presents an overview of a general six-step model that supports the development of evidence-based designs for OPD. This model contains three critical parts:

1. the model has to be based on insights in the neurological processes of OPD and the resulting behavioural consequences (step 1-3);

2. the model has to support the development of design principles and has to give a clue to translate these principles in design specifications (step 4 and 5); and

3. the model has to support creative processes in which design specifications are converted into concrete designs (step 6).

We would like to make three remarks about this model and its application. First, this model is quite ambitious. It tries to relate neurological processes and behaviour of OPD on the hand and design principles and design specifications for housing, interior and technologies on the other hand. To relate data from different disciplines requires an overall philosophy. There is no guarantee such a 


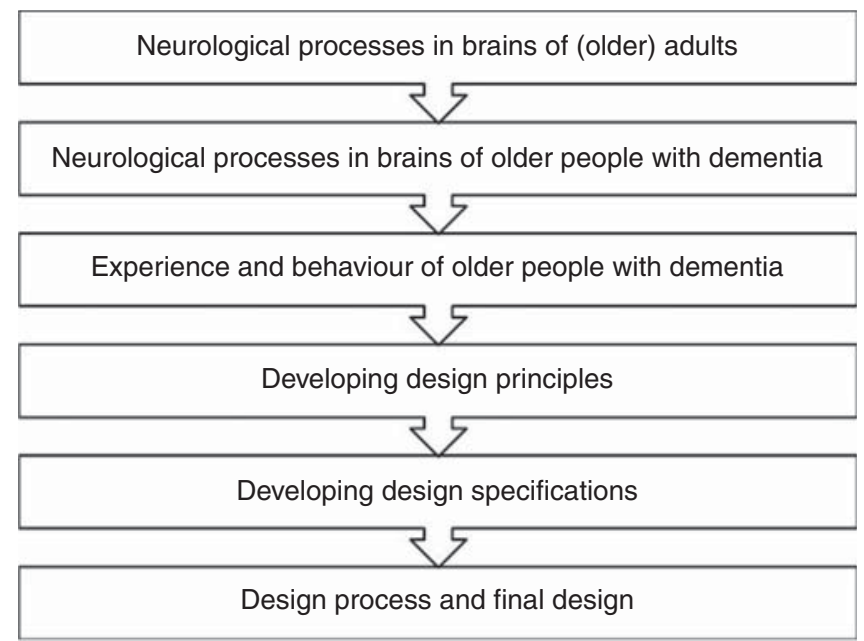

philosophy is available. Second, this model has the status of a hypothesis. The line of reasoning seems to be very logical. However, the model and every separate step has to be tested scientifically, which is an essential requirement of evidence-based design. In addition, its practical value for architects and designers has to be demonstrated empirically. Third, for practical reasons, there is a focus on older people with Alzheimer's disease, which is the most prevalent cause of dementia. It is believed that this model can also be applied to other types of dementia and to people with early onset dementia.

The research methodology for the steps 1,2 and 3 is a literature review (Seale, 2004). The most important selection criterion was to what extent papers gave insight into the relationship between neurological processes of OPD on the one hand and the daily behaviour of OPD on the other hand. The research methodology for step 4 is a combination of a critical review of design literature (Seale, 2004) and an extensive evaluation of case studies (Yin, 1994). The currently available literature does not present any guidelines to execute this step. The quality of the proposed design principles strongly depends on the skills and creativity of the researchers. The research methodology of step 5 is to select a suitable philosophical theory that has the ability to relate human behaviour and specifications for technological design (Verkerk et al., 2016). An absolute precondition for such a philosophical theory is that it provides insight in the nature of human beings, the character of technological artefacts, and the relationship between these two. For this step there is one practical consideration: the proof of the pudding is in the eating. The research methodology of step 6 is an empirical evaluation of case studies (Yin, 1994).

\section{Step 1: neurological processes and behaviour of older people}

The domain of neurosciences provides an increasing amount of knowledge on information processing (Goldberg, 2002). This section is focussed on information processing related to "normal older people" or "successful ageing" (Rowe and Kahn, 1997).

\subsection{Historical overview}

The British neurologist Jackson (1835-1911) was one of the first researchers to characterize information processing in the brain as a step by step process in which increasingly complex parts of the brain are involved (Meares, 1999). In the 1960s, Luria proposed that the brain is hierarchically organised (Luria, 1973). In his view, there is a hierarchy in the brain that consists of an increasing complexity of neurons combined with a "higher" location in the anatomical and functional brain that ranges from the brainstem to the frontal lobe. Subsequently, Powers (1973) distinguished different 
hierarchical levels of which the highest levels have the most sophisticated information-processing capacity. All these levels are actively part of the information processing within the brain (Cools, 1985). At present, over twenty hierarchical levels can be differentiated in the brain, which may be summarised into four groups (van der Plaats and Verbraeck, 2008) (Figure 2):

- level 1: maintaining homoeostasis, pain, hunger, primitive reflexes, reflex behaviour, waking, sleeping, sorting and arranging incoming stimuli, and so on (brainstem and formatio reticularis);

- level 2: concrete representation of context with a welling up of primary emotions (especially fear, fight or flight, pleasure and displeasure), automatic movement and language patterns and so on (amygdalae and hippocampus);

- level 3: consider own behaviour by consciously using key stimuli, memory, emotions, movement patterns, mental inhibition and so on (nucleus caudatus and nucleus accumbens); and

- level 4: planning tasks, start, keep up, adjust and stop, self-knowledge, awareness of others, awareness of time, choosing, generalisation and so on (dorsolateral and ventromedial prefrontal).

Levels 1 and 2 develop in the first years of our lives, and levels 3 and 4 develop until approximately 24 years of age. It is argued that, after the age of 24 , the brain starts to (slowly) deteriorate again. The onset of dementia impacts these levels in due course (van Hooren et al., 2005).

Simple information can be processed by the lower brain (levels 1 and 2); complex information requires actions from the upper brain (levels 3 and 4). With the use of the higher levels functions, possibilities that are offered in life or by the environment are explored and choices are made based on these possibilities. These higher levels functions include for exampling, planning, reasoning and problem solving. At the lower levels, the options for behavioural action are more restricted. These include more basic, physiological functions such as breathing, which are important for surviving of the individual.

\subsection{Neurological processes and behaviour}

Cools $(1985,2014)$ provided a detailed description of the relation between information processing in the different levels of the brain and behaviour. According to his theory, behaviour is always the result of how a person perceives the environment (i.e. situation) around him. This process is called perception. Consequently, certain behaviour may emerge in case of misunderstanding a situation. This behaviour may be perceived as inadequate by others.

Our brain is hierarchically organised in lower and higher levels (). According to Cools (2013a, b), the various levels in the brain process different information. Dynamic stimuli (everything that moves or produces sound or light) may be processed by the lower levels and static stimuli (everything that does not move or does not produce sound or light) may be processed by the higher levels. Cools (2013a, b) also suggested that stimuli are sorted and ordered, and reflexes are being generated at the lowest level of the brain. At level 2, an image is created on the basis of dynamic stimuli (movement, sound), which is also processed in terms of safety. Spontaneous, unchecked emotions find their origins here. If these emotions are not managed by the higher levels they may

Figure 2 Simplified hierarchical model of the functioning of the brain

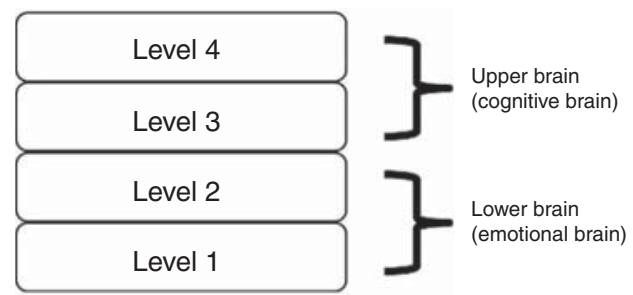

Source: van der Plaats and Verbraeck (2008) 
result into fight or flight behaviour (Cools, 2013a, b). Another important function of these higher levels is mental inhibition. Impulses are constantly being slowed down and disruptive stimuli are being disposed of in order to obtain adequate behaviour-under-control (Goldberg, 2005).

The perception process occurs by means of so-called neural representations (Ratey, 2003). They are like vivid images (concrete or abstract) of the situation. In the lower levels relatively simple, concrete and less complex neural representations are formed. In the higher levels, the information send through by the lower levels can be processed into sophisticated, well-chosen and abstract plans of action with possible alternatives. The higher levels consciously supervise some of the lower levels, such as postponing needs and inhibition of impulses. In general, human interactions are so complex that higher levels are needed to process the input. According to this theory damage to these levels of the brain may lead to inadequate behaviour which may be labelled as "problem behaviour" or, more generically, behavioural symptoms.

\section{Step 2: neurological processes of OPD}

Altered behavioural and psychological symptoms are seen in many OPD (Perry et al., 2017; O'Callaghan et al., 2016). On average, six types of behavioural symptoms are observed (Zuidema, 2008, pp. 49-63). Behavioural symptoms that are quantified as most burdensome are calling out, aggression and obsessive walking (Kearns et al., 2009). Hence, the question that rises is:

$R Q 1$. What goes on in the brain that drives OPD to these behavioural symptoms?

Information processing by OPD differs from that of older adults who do not have dementia. The most important difference is the decreasing capacity to process (complex) stimuli, which has a strong influence on behaviour. Van der Plaats (2010) has given an overview of characteristics that should to be considered in the design and evaluation of the environment:

1. The brain may only handle dynamic stimuli: for instance, stimuli that are moving or producing sound.

2. "Static" stimuli (without movement or sound) cannot be perceived correctly. In a static environment the person with dementia has to produce stimuli himself or herself by wandering, moving obsessively or making sounds.

3. In catching "dynamic" stimuli, there is a strict principle: only stimuli from one source of stimulation can be processed at a time. The brain has lost its capacity to select different sources of dynamic stimuli.

4. Dynamic stimuli within the direct sight-field of the OPD are processed. Stimuli coming from outside the direct sight-field, for instance, behind a person, may create chaos in the brain.

5. Voluntary and purposeful movements cannot be made by the cognitive part of the brain. OPD may not be able to initiate an efficient action on their own, or as the result of a single verbal instruction.

6. OPD need meaningful stimuli to initiate actions. Meaningful stimuli are stimuli in a specific context. These stimuli are processed by the lower brain.

7. These meaningful stimuli include a familiar environment based on their own technological generation, the right starting position of the body, an emotion or sense of humour, inviting music or songs, the option to imitate someone else (a real person or a person on a screen), or "persuation" to act, especially by small animals or children.

8. Mirror neurons give people the possibility to imitate proper actions. Mirror neurons "fire" not only when a person performs a certain action, but also when a person is watching another person performs the same action. It has been argued that mirror neurons remain largely intact in OPD (Rizzolatti et al., 2009). However, a more recent study suggest otherwise (Moretti, 2016).

All these changes in the neurological processes may influence the behaviour of OPD. In designing environments we have to take into account that people with advanced stages of dementia may have difficulties in taking initiative, initiating actions and motion, and working their way through the environment. 


\section{Step 3: experience and behaviour of OPD}

The neurological processes in the brains of OPD are impaired because of the underlying pathologies. Levels 3 and 4 of the brain's functioning are impaired in such a way that visuospatial processing (Jacobs et al., 2015), voluntary switching in cognition or movement, adapting to circumstances (O'Callaghan et al., 2016), planning, and decision making may have pronounced deficits (Delazer et al., 2007; Zamarian et al., 2010). These kinds of deficits may have a severe impact on everyday functioning since real-life situations are complex and require various combinations of brain functions (Zamarian et al., 2010). Consequently, if these functions are damaged, the behaviour that OPD display may be ill-fitted.

\subsection{Information processing in the impaired brain}

Maintaining a high quality of life in older age requires advantageous decision making in domains such as finances, health care, use of technology and housing situations (Zamarian et al., 2010; Kazak et al., 2017). Hence, decision making is an important ability for independent living. OPD are confronted with extreme difficulties in decision making, especially when decision making is complicated by means of time-pressure or poorly structured situations.

Complex situations, in which decision making is required, are processed in the damaged upper brain, and may create a state of chaos in the minds of OPD (Cools, 2011, 2013a, b). The subsequent behaviours may be dictated by feelings of anxiety and anger. These behaviours affect the well-being of OPD, and are difficult to handle and are usually not well understood by carers. All the input to the brain should be fitting for the cognitive abilities of OPD in order for them to cope with the situation at hand. In conclusion, OPD slowly lose their capacity to organise their behaviour "voluntarily" and become increasingly dependent on the environment (Cools, 2012).

The amygdalae were originally "intended" to recognise danger by way of a quick screening of the environment. It determines behaviour programmed in level 2 (Jablonski et al., 2011). The activation of the amygdalae generates fight (aggression), flight (run) or freeze behaviour in stressful situations. Without the moderating qualities of the higher level systems this behaviour is non-reflective, impulsive and reactive (Phelps and Anderson, 1997). Neuroanatomical changes to the amygdala therefore also alter behaviour in OPD (Wachinger et al., 2016). It is, therefore, essential to present every situations as safe and pleasant. This means we need to create environments that feel secure and offer a protective atmosphere.

\subsection{The environment as key determinant of behaviour}

In normal brain-functioning there is a mutual interaction between a person and the environment (Perry, 2002). Research shows that the impaired brain becomes increasingly dependent on the environment at hand (Goldberg, 2010). In other words, the person-environment relationship is damaged and the environment becomes a key determinant for behaviour (Cools and Ellenbroek, 2002; Cools, 2012; Colombo et al., 2017). An important part of understanding the environment around onself, are stimuli. Stimuli are defined as "something that incites to action or exertion or quickens action, feeling or thought". Especially for OPD, the environment should incorporate a perfect balance in stimuli (Cohen-Mansfield et al., 2010). In order to prevent inadequate behaviour, a "balance" in stimuli has to be present.

Two types of imbalance in the amount of available stimuli might occur: an overload and an underload. In case of an underload of stimuli, the brain may switch to a state of dismay. The result is that the person with dementia may create his or her own stimuli by making obsessive sounds or movements like shouting, plucking, walking or obsessive sleeping (van der Plaats and Verbraeck, 2008). These behaviours may occur in situations without dynamic stimuli, such as in quiet private rooms, in a chronic bedfast situation, and at night alone in bed (van der Plaats and Verbraeck, 2008). These behaviours may act as stressors for professional caregivers and relatives. In order to avoid such behaviours, sources of dynamic stimuli, like moving coloured led-lights (in private sleeping rooms), appealing DVDs (in silent living rooms) and the so-called experience areas in corridors (in order to stop obsessive wandering) are created in practice (de Koning, 2012). In contrast, an overload of dynamic stimuli may arise, for example, when several carers are talking 
with each other while the television is on, and people are walking in and out. As a result, OPD may become restless and scared, which may result in shouting or behaving angrily or hostile

Consequently, a perfect balance regarding stimuli has to be found for people with dementia. We would like to coin the idea of designing for a balance of stimuli as "designing for a favourable state". In order to acquire such an equilibrium, there are several considerations. First, one should consider all stimuli that are not in the person's immediate field of vision. These stimuli may cause unwanted distractions (van der Plaats and Verbraeck, 2008). For example, when a OPD hears a noise, but may not know where the noise comes from and as a consequence, may get frightened. When designing housing and supporting technologies for OPD it is of utmost importance to prevent such unwanted stimuli. So, one should design rooms when nursing aides or paid carers cannot walk behind OPD or engage in conversations with them or other people when the OPD cannot see them. Furthermore, floor covering should be used in order to prevent the transfer of noise from hard soled shoes, and other sources of distracting noise from entrance-doors, kitchen equipment and the TV coming from behind should be limited. Seats should be backed to the walls and the OPD should be able to see all the emerging dynamic stimuli in the room.

Second, a great deal of the visual stimuli gets lost in the lower brain and is not processed. Therefore, the environment may be perceived only vaguely. OPD need higher light levels in terms of daylight and illumination, and bright and contrasting colours (Day et al., 2000; van Hoof, Kort, van Waarde and Blom, 2010). Examples of non-supporting design include furnishing in only one basic colour, bathrooms all in white, and walls in pastel (Brawley, 1997).

Third, the memory in dementia reverses to the neural representations of youth and early adulthood. Modern contexts, technologies, objects, words, noises and food are often unrecognised as the dementia progresses. This has an enormous impact on how things have to be designed. The environment has to be in tune with what interior designs and technology looked like when still young and when the brain was still developing. This has ever evolving consequences for the layout of buildings and the choice of furniture and technology, as styles and technological styles succeed each other with ever greater speeds.

These abovementioned considerations regarding OPD, stimuli and design, provide insights in the manner in which environments for OPD can best be designed. In conclusion, an institutional setting aimed at caring for OPD, can be improved by simply looking at how the brain of OPD handles stimuli in the near environment (Cohen-Mansfield et al., 2010).

\subsection{Beautiful moments}

In the foregoing section it was shown that both an underload and an overload of stimuli can result in aberrant behavioural responses. On the other hand, the right "dosing" of stimuli might create the perfect condition that OPD may function at the higher brain levels. We have coined the term "beautiful moments" to describe these.

Beautiful moments can be evoked spontaneously by (dynamic) stimuli from the environment that are adapted to level 2. The creation of an old-fashioned context can facilitate purposeful behaviour. For instance, in an old-fashioned church or chapel, people with dementia can sing psalms, make the sign of the cross, and talk about God. In a similarly old-fashioned cinema, people can sit down and enjoy a black and white movie.

\subsection{The power of the environment}

OPD may experience a reduced quality of life when the environment does not match their sensory needs. So-called "stimuli in context" are needed in a fitting environment, which "seduce" the person to conduct the expected action. These contextual stimuli include the characteristics of category vii of the overview of Van der Plaats (2010) described at Step 2. Various design guidelines can help designers and architects to create such environments (Brawley, 1997; Day et al., 2000; Calkins, 2009; van Hoof et al., 2009; van Hoof, Kort, van Waarde and Blom, 2010; Marquardt et al., 2014), for instance, the design of familiar taps in kitchens and bathroom that can be recognised and used as such (Boger et al., 2013) or the use of pictures for environmental orientation (Motzek et al., 2017). 


\section{Step 4: developing design principles for housing and interior for OPD}

The challenge of this section is to translate these insights of the preceding sections into design principles. Such a translation requires a deep insight in the relationship between human behaviour on the one hand and design specifications on the other hand.

OPD are subject to "normal" ageing processes such as decrease in the sense of hearing, eyesight and mobility (van Hoof, Kort, Duijnstee, Rutten and Hensen, 2010). Consequently, the principles for designing for dementia ideally include principles that are applicable for the ageing population in general. The principles for designing for OPD are mentioned below.

\subsection{Design for ageing people}

OPD are ageing people themselves. In Section 3 we have investigated the neurological processes in brains of OPD. In Section 4 we have related these insights to the experience and the behaviour of OPD. It was argued that OPD have difficulties in taking initiatives, handling complexity, making up their mind, and interacting with the environment. Both an overload and an underload of dynamic stimuli might result in inadequate behaviour. A balance of stimuli prevents inadequate behaviour and supports meaningful behaviour. The idea of designing for a balance of stimuli as "designing for a favourable state" was coined (section 5.2). It has to be noted that all OPD have their personal characteristics and thresholds. Apart from these design aspects, designers should always consider the needs for safety and security when designing for OPD (van Hoof, Kort, van Waarde and Blom, 2010). The second principle for designing housing and technology for OPD is.

\subsection{Design for a favourable state}

OPD need an environment with a controlled level of stimuli. OPD can achieve a higher level of functioning including having social contact, enjoying beauty and experiencing spirituality. Such a state only can be realised when there is no excessive stress that induces a fight or flight response. Therefore, these higher functions only can be activated when the OPD are in a favourable state and when the environment offers the right stimuli at the right time and place in order to initiate and to support these higher functions: "designing for beautiful moments" (section 5.3). These stimuli depend strongly on personal characteristics and should be a research topic for future studies.

\subsection{Design for beautiful moments}

OPD may function on higher brain levels when the environment offers the right stimuli at the right place and the right time. Overall, this leads to a three-stage design model describing the general design principles for OPD (Figure 3).

\section{Step 5: translating the design principles into design specifications}

The design principles as formulated in the preceding section supports designers in asking questions related to the development of design solutions. For example, the first principle leads to the question: "What light levels are required to support the vision of older people?" The second one to "How to design a living room and technology to prevent an overload of stimuli?", and the third one to "How to design a sacred space to initiate and to support spiritual experiences?" All these questions have the same structure. They ask how specific elements of a design have to

Figure 3 General design principles with respect to OPD

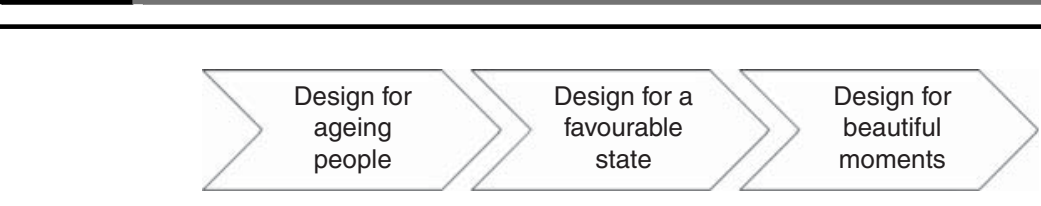


be designed in order to support the different ways of functioning of OPD. The development of an integrated method "to translate" design principles into design specifications requires some philosophical building blocks.

\subsection{Philosophical distinctions}

The Dutch philosopher Dooyeweerd (1969) made a distinction between "aspects" and "wholes". A whole is an entity with an own character and every whole functions in different aspects. Dooyeweerd (1969) describes in his theory of modal aspects that every whole or entity functions in different aspects or dimensions. For example, a human being needs food (biological aspect), thinks in a rational way (logical aspect), interacts with other people (social aspect), buys and sells products (economic aspect), and cares for others (moral aspects) (Verkerk et al., 2016, pp. 62-85). Dooyeweerd (1969) describes in his theory of individuality structures that every whole or entity has its own character or identity. For example, an enterprise is economically qualified, a court judicially, a piece of art aesthetically, and a church religiously.

\subsection{Theory of modal aspects}

The theory of modal aspects states that every whole functions in different aspects or dimensions (Verkerk et al., 2016, pp. 62-85). This theory is important to understand and to map the different modes of functioning of OPD and to define design requirements that have to support these different modes of functioning. Dooyeweerd (1969) distinguishes in total 15 different aspects of modes of being (Figure 4). By means of an in-depth analysis, Dooyeweerd argued that all these dimensions have their own character. For example, the nature of the biological aspect of a person with dementia is quite different from the nature of the psychic or sensory aspect. The dynamics of the social interaction for OPD are quite different from the subtleties of a spiritual experience. In other words, every dimension has its own dynamics, mechanisms, laws, and norms. Technological artefacts and long-term care facilities have to support the different modes of functioning of OPD. This means that specific specifications have to be developed to support the biological functioning, the psychological aspect, and the social and spiritual aspects. In conclusion, a multidimensional specification has to be developed in which all different aspects of the functioning of OPD have to be addressed.

Figure 4 The many aspects or dimensions of our reality

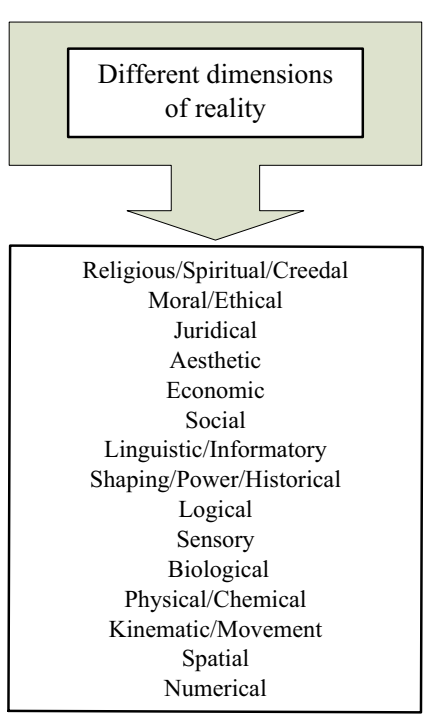

Source: Dooyeweerd (1969) 


\subsection{Theory of individuality structures}

The theory of individuality structures supports us to understand the identity of wholes, for instance, the identity of a long-term care facility. Dooyeweerd (1969) emphasised that human beings cannot be characterised by one aspect or dimension. Humans are not only social beings but also rational beings, not only moral beings but also spiritual beings. Consequently, it is the challenge of health care to support all different aspects or dimensions in which humans function. The identity of a long-term care facility can only be understood from its function to care for OPD. The design of the technology, private rooms and kitchen areas all (have to) reflect this basic function. So, the identity of a long-term care facility is determined by "caring for", i.e. the moral dimension. In the Dooyeweerdian terminology: the different functions of a long-term care facility have to be disclosed by the objective of caring for OPD. This formulation has firm implications for the design of the whole facility. For example, the social room is not a "simple" social room (qualified by the social aspect) but a social room that supports the social behaviour of OPD. In other words, it is disclosed or marked by the moral aspect of caring for. Another example is the design of the chapel. The chapel in a long-term care facility is not a standard design that supports religious activities but it is a design that supports religious experiences of OPD.

\subsection{Developing a multidimensional specification}

The philosophical concepts presented in the previous sections support the translation of design principles into design specifications. There are two methods to develop a multidimensional specification. The first method is to take the design principles as a starting point and to explore the different aspects systematically. The second one works the other way around. In our view, the first method is more appropriate. This section presents some examples to show the power of the methodology. The starting point lies in the functioning of OPD, particularly the biological up to religious aspects are relevant (Figure 4).

Principle 1: design for ageing people. As mentioned before, OPD are subject to normal biological ageing processes. That implies that designers first have to ask themselves how a certain aspect or dimension of the human being is influenced by the ageing process. Thereafter, one can translate that aspect or dimension in a design specification.

Biological aspect. Older people may have perceptual problems concerning the ambient temperature. This aspect can be translated in a set of design specifications, like control of the temperature of the indoor air, the design of thermostats and the use of radiant heating. Older people may be prone to falls, and emergency response systems in and outside the home may be necessary.

Sensory aspect. Older people may experience a decline in vision. This aspect can be translated in design specifications relating to the intensity of light and the level of contrast.

Logical aspect. Older people may have a decreased cognitive functioning. This aspect can be translated into designing for familiarity and adhering to logical structures.

Social aspect. Older people face more difficulties in making new social contacts and may experience loneliness. This requires solutions that stimulate social interaction and engagement.

Moral aspect. Being human is being a fellow being; being human implies giving care to others and receiving care in return. The environment should support older people taking care for others or of their pets.

Principle 2: design for a favourable state. The idea of designing for a favourable state is to guide behaviour by a controlled level of stimuli, preventing both an overload and an underload of dynamic stimuli. Dynamic stimuli are related to subtle changes and motions in the environment, such as people passing by, the sound of music and certain activities.

Sensory aspect. Too much motion around the OPD leads to an overload of stimuli and may result in restlessness. Therefore, the design of the living room should prevent nurses from "running around". Furthermore, excessive noise from technology leads to an overload of stimuli and may result in agitation. The acoustics and music systems have to be designed in such a way that the 
noise level can be controlled, without the risk of an underload. The sensory needs of all the OPD present in the shared space needs to be met., Of course, this is a tremendous challenge, since the threshold for under-or overload may differ per person.

Social aspect. The living room should be designed in such a way that it limits the number of people and provides places for withdrawal.

Economic aspect. The shop in the long-term facility has to be designed in such a way that OPD easily can find their way and can buy the articles they need.

Principle 3: design for beautiful moments. OPD can function on higher brain levels when the environment offers the right (amount of) stimuli at the right place and at the right time. The theory of modal aspects clearly shows the richness of human functioning. The design for beautiful moments can disclose all the different modes that belong to typical human activities: logical thinking (jigsaws, riddles), self-direction (shaping life, making decisions), language and symbols (talking, reading, understanding the meaning of symbols), social intercourse (drinking and talking together), economic transactions (shopping), experience of beauty (nature, art), treating older people fairly and justly (respect their interests and biography), love and care (for others), and spiritual experiences (chapel, singing together, praying). OPD indicate that they find these modes of functioning very important (Dröes et al., 2006). However, OPD cannot always initiate these modes of functioning by themselves but these modes have to be initiated and steered by the environment and its components including technology. When designing for a beautiful moment, a designer should focus on the qualifying aspect of an activity.

Social aspect. The qualifying aspect of a living room is the social aspect. An environment should offer options for meaningful interaction with others. It should not only prevent an underload or overload of stimuli (design principle 2), but it should also invite and support OPD to engage in social interactions with others.

Religious aspect. The qualifying aspect of the chapel is the religious aspects. It should offer OPD the possibility to give expression to their religious beliefs, even if their active participation in religious services and traditions is limited.

In conclusion, the Dooyeweerdian philosophy offers a means of linking the different aspects in which humans function and the different environments in which they live. This philosophy can be used to translate design principles to design specifications in a systematic way by mapping the different aspects.

\section{Step 6: the creative process from design specifications to concrete designs}

This section presents case studies to illustrate the model by describing the design of a living room, part of a corridor, baby room and chapel. The re-design of parts of corridors stemmed from the wish from the nursing home management to transform an unattractive corridor into a more appealing and interactive space for OPD to explore and enjoy.

\subsection{Design of a living room}

Most nursing homes have one or more living rooms. The identity or qualifying aspect of a living room is the social aspect: living together with co-residents, social contact with relatives, and interaction with staff (Rijnaard et al., 2016). Plate 1 presents a design of a living room. Windows are essential elements, but should not reach down to the floors, as OPD may not be able to tell the difference between inside and outside. People may actually try to step outside and hit the window pane, or experience cold sensations as they think a door has been left open. A solution to such design flaws could be the introduction of raised window sills or sticking foils to the windows to cover the lower part up. Windows that lead to the corridor should be covered by net curtains, so that people walking by do not form a source of distraction. If there are no curtains inside the room, people may think they are either moving out or having spring cleaning. In the evening, they may see their own mirror images in the window, faces they do not longer recognise and which leads to fear. 


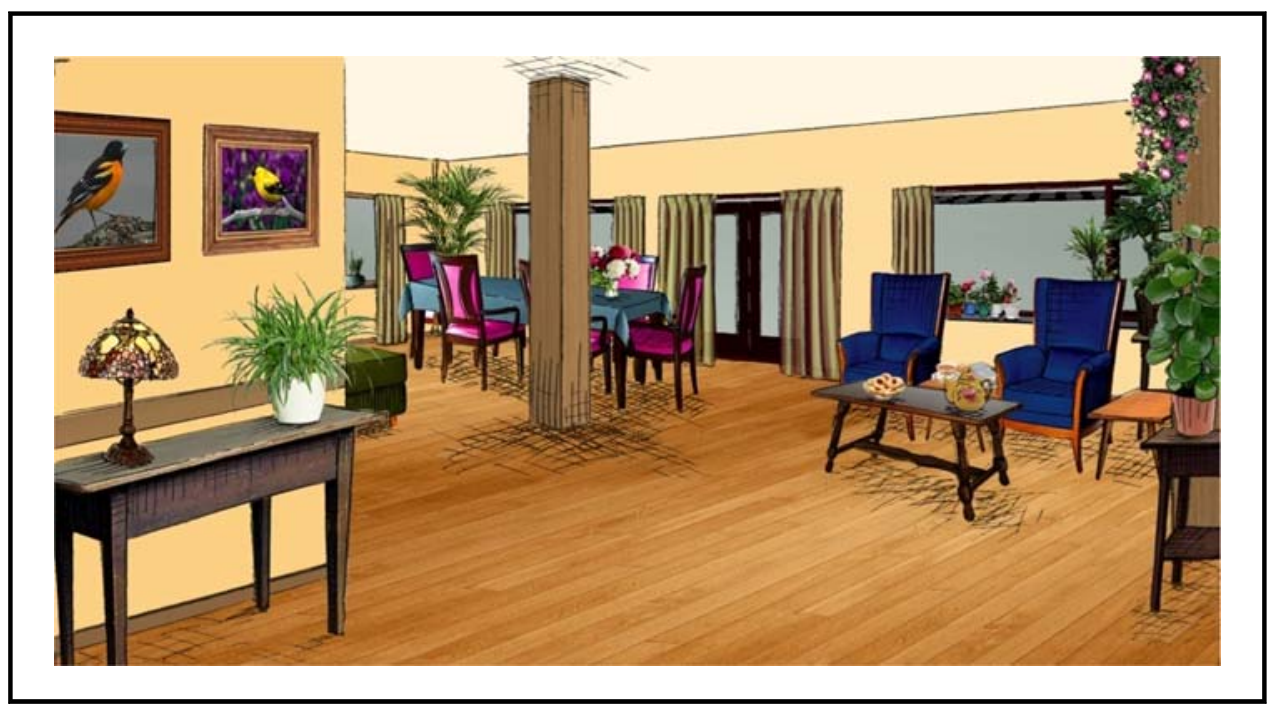

Ideally, the dining table is positioned next to a window, and residents can enjoy their breakfast there and sit around the table. Another solution that should be considered is having multiple smaller dining tables. It can be quite burdensome to be sitting around the table with multiple co-residents for a long time as one may be offended by someone else's lack of decorum. Small square tables may do the trick, but one should be aware that in case of wheelchairs, the foot board should not touch the person sitting opposite. Based on intuition and character, people can choose their own table mates, and be together and interact. In a group with eight individuals, two tables are sufficient, and perhaps, a third small table should be considered for allowing additional guests or creating flexibility. In practice, however, there is no question of "one group of eight people" but "eight groups of one person" showing the complexity of the social interactions and its moral implications.

When designing the living room, it is important to stress and define the two functionalities of the room: dining on the one hand, and relaxation on the other hand. Large armchairs and a fire place should be designed in overdrive: the stereotypical design may contribute to recognition and familiarity. The seating area should have a different colour from the dining area. This contributes to a spatial distinction between the two functionalities (so-called zoning). The use of sofas in the living room should be avoided, as people will use sofas as beds. A sofa can be qualified as a waste of space, because no one will sit down next to someone sleeping on a sofa unless they are friends.

In order to create visual borders, one could mount horizontal wooden elements onto the wall, as a sort of mock wainscoting or panelling. It allows people see where the borders of a room are, and if there are corners inside. A window sill can also be a horizontal element that defines the borders of a space. The wall surface below the window sill or wooden slat can be painted in a different colour.

\subsection{Re-design of a part of a corridor}

Many corridors nursing homes are dull and designed to support the transfer people and goods. However, there are various design solutions to transform corridors in places where OPD can experience beautiful moments. In this case the aesthetic aspect of human functioning is activated by transforming a dull alcove in a corridor into an indoor garden experience corner (Plate 2). This corner should be appealing for the emotional part of the brain. If OPD wander around in the corridor, they are drawn in by a green light shining down on the floor, coming through green sticky foils that were put on the window pane. When residents come near, they walk through an infrared beam from floor-mounted sensor. When this sensor is activated, bird songs start to play. The same birds can be found sitting on the branches of the artificial trees, as well as an owl. 
Some relatives stated that this corner provided topics for conversation, and they experienced this corner as a part of an adventurous route through the nursing home. Many variations on the theme can be made in practice.

\subsection{Design of a baby room}

Existing alcoves in corridors also can be used to enable OPD to enjoy beautiful moments by caring for others. In this case the moral aspect of human functioning is activated. A baby room was designed to

Plate 2 Pictures of before (a) and after (b, c) turning an alcove in the corridor into a garden experience corner. It should be noted that picture (c) shows the wall of the alcove that is not visible in picture (b)

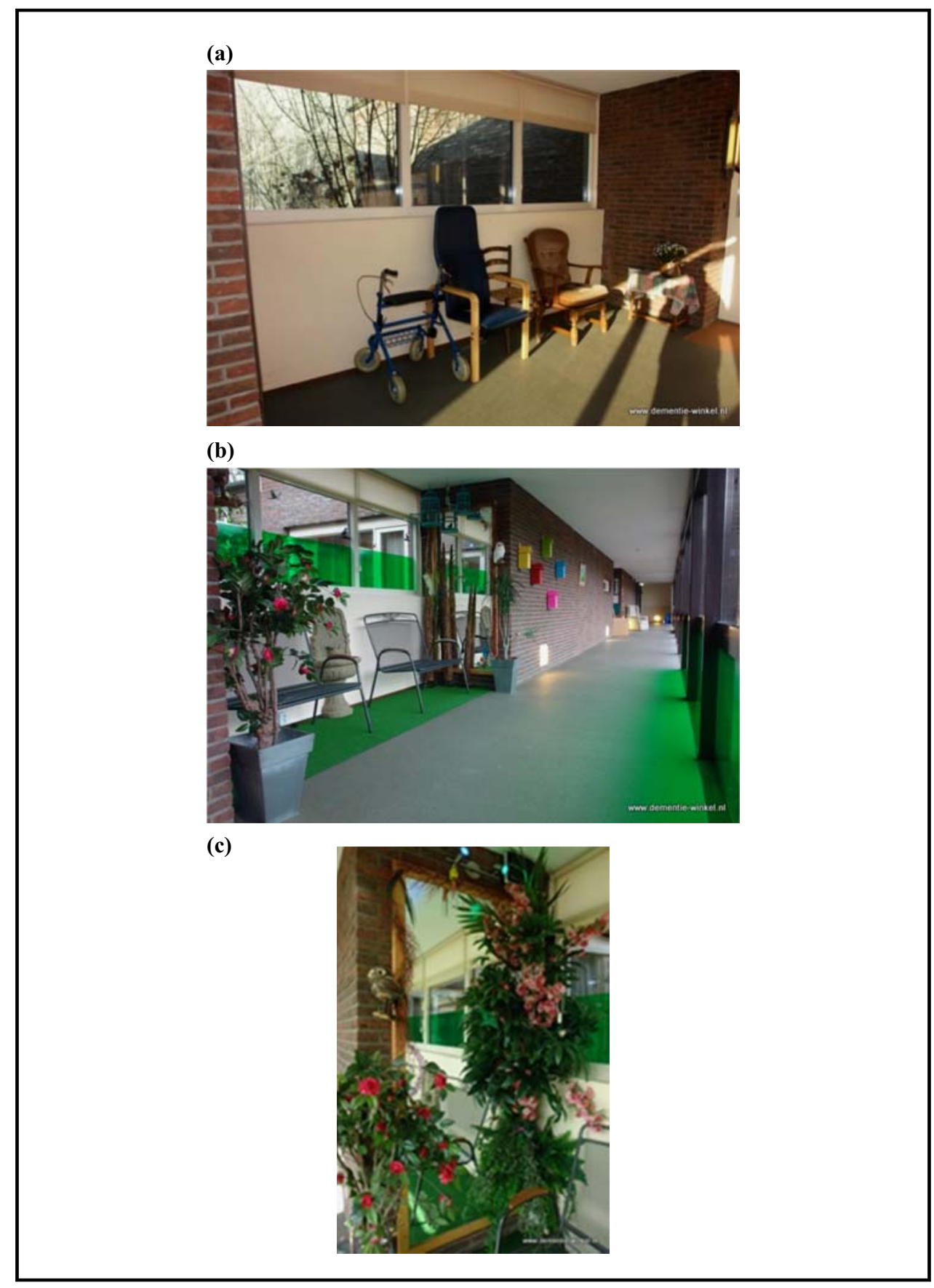


offer an environment to initiate purposeful actions (Plate 3), which are related to doll therapy (Pezzati et al., 2014). At first glance this design appeared to be controversial. Regularly, family members asked critical questions suggesting that this room infantilises their beloved ones. After explaining the ideas behind this design, the criticism gradually ceased. However, this does not alter the fact that the question must be asked what a good design is to invite OPD to care for others.

In this baby room, the foil stuck onto the window pane is pink. Based on a sensor that is activated when walking by, a baby doll starts giggling and making baby sounds. These sounds are somewhat louder than normal, as older people should be able to hear well. The sounds only turn off when people leave the corner. Even though this corner is intended particularly for use by women, some men are attracted too. The intervention provides a number of stimuli that invites OPD to care. For example, the baby doll is placed on top of a chest of drawers, or inside a cradle. Baby clothes lie around. Some of the drawers of the chest of drawers are half-open, and clothes stick out. Some women start folding these clothes and put them back into the drawers neatly. Changing diapers is another activity that can be carried out in the experience corner.

\subsection{Design of a chapel}

The last example is related to the spiritual aspect of human functioning and concerns an alcove that was redesigned for worshipping. Many people have experienced support from religion throughout their lives and value religious rituals and festivities. It has to be noted that the choice of design elements is critical: for a Roman Catholic or Jewish chapel different symbols, images and architectural elements have to be applied. An alcove is a fitting space to redecorate as a religious space, as it resembles the type of space that people are used to from their previous church life. The existing window pane was turned into a stained glass window using paint. A slowly rotating light was placed behind, which makes a spectrum of colours shine onto the ceiling and the walls, just like a kaleidoscope. The colours of church are also applied on the walls of the corridor, as a means to draw in people or draw people towards the chapel. Two large candle sticks are placed in front of the alcove. The mock candles, which were battery-operated, burnt continuously. There is a sensor in the corridor which activated songs of worship or psalms. The room itself was large enough for three people, including the priest or religious worker. Inside the space was a large cross, and a small table that serves as the altar. There were two chairs for sitting.

\section{Conclusions}

The objective of this paper was to inform architects and designers in order to improve environments for OPD. Based on the constructions formulated in this paper, an environment can

\section{Plate 3 Pictures of before (a) and after ( $b, c)$ turning an alcove in the corridor into a} baby room

(a)

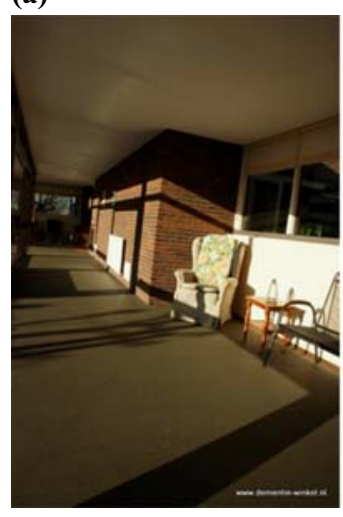

(b)

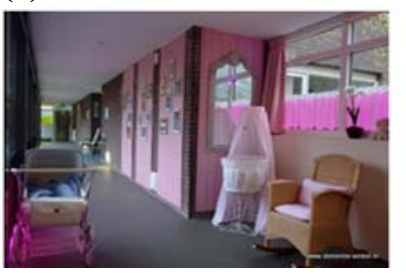

(c)

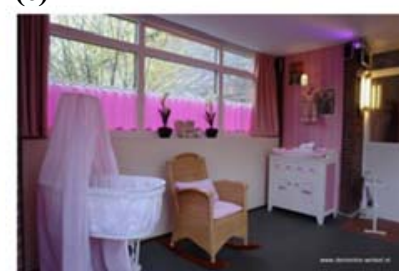


be formed that matches the current needs and wishes of OPD. This paper needs to be viewed in the light of the past: there used to be an enormous focus on medical treatment for OPD. Nowadays, we know that excellent medical care is not enough. Neurology and behavioural sciences present insight in the brain processes, the behaviour, and the desires of OPD. These insights show the need of a paradigm shift. Instead of presuming that problematic behaviour in dementia arises directly from impairments to the brain and that requires medical interventions, there is a growing awareness that the environment plays a crucial role.

The first aim was to develop a general model for designing the building, its interior and technologies for OPD. We developed a general model that has a firm scientific foundation in neurology, behavioural sciences and philosophy. This model consists out of six distinct steps and for each step we presented some empirical evidence and/or theoretical arguments. However, the whole model, its distinct steps and its assumptions should be further tested and refined though empirical research. It is possible that parts of the model do not work and the concerning foundations have to be changed.

The second aim was to identify principles for designing the environment for OPD. The housing, interior and technologies should initiate positive behaviours and meaningful experiences. Based on neurology, behavioural sciences and design theories, three design principles were developed: design for ageing people, design for a favourable state and design for beautiful moments. These principles have to be applied in a logical and subsequent order. Also for these principles hold that they should be tested and refined though empirical research.

The third aim was to develop a methodology to translate design principles in design specifications. We developed such a methodology based on the theory of modal aspects and the theory of individuality structures as developed by the Dutch philosopher Dooyeweerd. We presented some examples that illustrated the used of this methodology. More research is required to validate this methodology and to test its practical applicability.

In conclusion, in this paper we have presented a methodology and three design principles that support architects and designers in designing an environment that matches the needs and wishes of OPD. The methodology and design principles are developed based on theoretical considerations and empirical data. Future research is required in order to build a proper foundation for this approach and to show its practical applicability.

\section{References}

Boger, J., Craig, T. and Mihailidis, A. (2013), "Examining the impact of familiarity on faucet usability for older adults with dementia", BMC Geriatriacs, Vol. 13, p. 63.

Brawley, E.C. (1997), Designing for Alzheimer's Disease. Strategies for Creating Better care Environments, John Wiley \& Sons, Inc., New York, NY.

Calkins, M.P. (2009), "Evidence-based long term care design", NeuroRehabilitation, Vol. 25 No. 3, pp. $145-54$

Charras, K., Eynard, C. and Viatour, G. (2016), "Use of space and human rights: planning dementia friendly settings”, Journal of Gerontological Social Work, Vol. 59 No. 3, pp. 181-204.

Cohen, U. and Weisman, G.D. (1991), Holding on to Home: Designing Environments for People with Dementia, The Johns Hopkins University Press, Baltimore, MD.

Cohen-Mansfield, J., Marx, M.S., Dakheel-Ali, M., Regier, N.G. and Thein, K. (2010), "Can persons with dementia be engaged with stimuli?", Am J Geriatr Psychiatry, Vol. 18 No. 4, pp. 351-62.

Colombo, D., Serino, S., Tuena, C., Pedroli, E., Dakanalis, A., Cipresso, P. and Riva, G. (2017), "Egocentric and allocentric spatial reference frames in aging: a systematic review", Neuroscience and Biobehavioral Reviews, Vol. 80, pp. 605-21.

Cools, A.R. (1985), "Brain and Behaviour: hierarchy of feedback systems and control of input", in Bateson, P.P.G. and Klopfer, P.H. (Eds), Perspectives in Ethology, Vol. 6, Plenum Press, New York, NY, pp. 109-68. 
Cools, A.R. (2011), "The Erlangen instrument of alternating word fluency in Dementia", Journal of Gerontopsychology and Geriatric Psychiatry, Vol. 24 No. 3, pp. 137-42.

Cools, A.R. (2012), "Dementia: a progressive disease during which the brain makes the subject increasingly dependent on environmental stimuli", Gerontechnology, Vol. 11 No. 2, pp. 278-9.

Cools, A.R. (2013a), "Fronto-stratial atrophy correlates of inhibitory dysfunction in Parkinson's disease versus behaviour variant in fronto-temporal dementia”, Cortex, Vol. 49 No. 7, pp. 1833-43.

Cools, A.R. (2013b), "Promoting the executive functions", in Randolph, J.J. (Ed.), Positive Neuropsychology, Springer, New York, NY, pp. 77-110.

Cools, A.R. (2014), "Animal models for brain research", in van Dam, D. and de Deyn, P.P. (Eds), PET and SPECT of NeuroBiological Systems, Springer, Dordrecht, pp. 5-35.

Cools, A.R. and Ellenbroek, B.A. (2002), "Animal models of personality”, in D'haenen, H.A.H., den Boer, J.A. and Willner, P. (Eds), Biologicalm Psychiatry, John Wiley \& Sons, Chichester, pp. 1333-44.

Day, K., Carreon, D. and Stump, C. (2000), "The therapeutic design of environments for people with dementia. A review of the empirical research", The Gerontologist, Vol. 40 No. 4, pp. 397-416.

de Koning, S.J.M.M. (2012), "The right stimuli, on the right time, on the right spot, can make Old Alice feel happy”, Gerontechnology, Vol. 11 No. 2, pp. 278-9.

Delazer, M., Sinz, H., Zamarian, L. and Benke, T. (2007), "Decision-making with explicit and stable rules in mild Alzheimer's disease", Neuropsychologia, Vol. 45 No. 8, pp. 1632-41.

Dooyeweerd, H. (1969), A new Critique of Theoretical thought, The Presbyterian and Reformed Publishing Company, Philadelphia, PA.

Dröes, R.-M., Meiland, F.J.M., Schmitz, M.J. and van Tilburg, W. (2006), "Effect of the meeting centres support program on informal carers of people with dementia: results from a multi-centre study", Aging and Mental Health, Vol. 10 No. 2, pp. 112-24.

Ebersole, P., Hess, P. and Schmidt Luggen, A. (Eds) (2004), Toward Healthy Aging, 6th ed., Mosby, St. Louis, MO.

Feddersen, E. and Ludtke, I. (2011), Living for the Elderly: A Design Manual, Birkha:user, Basel.

Fischer, J. and Meuser, P. (2009), Construction and Design Manual - Accessible Architecture. Age and Disability-Friendly Planning and Building in the 21 st Century, DOM Publishers, Berlin.

Goldberg, E. (2002), The Executive Brain. Frontal Lobes and the Civilized Mind, Oxford University Press, Oxford.

Goldberg, E. (2005), The Wisdom Paradox, Oxford University Press, Oxford.

Goldberg, E. (2010), The New Executive Brain. Frontal Lobes in a Complex World, Oxford University Press, Oxford.

Hadjri, K., Rooney, C. and Faith, V. (2015), "Housing choices and care home design for people with dementia", Health Environments Research \& Design Journal, Vol. 8 No. 3, pp. 80-95.

Jablonski, R.A., Thierrien, B., Mahoney, E.K., Kolanowski, A., Gabello, M. and Brock, A. (2011), "An intervention to reduce care-resistant behavior in persons with dementia during oral hygiene: a pilot study", Special Care Dentist, Vol. 31 No. 3, pp. 77-87.

Jacobs, H.I.L., Gronenschild, E.H.B.M., Evers, E.A.T., Ramakers, I.H.G.B., Hofman, P.A.M., Backs, W.H., Jolles, J., Verhey, F.R.J. and van Boxtel, M.P.J. (2015), "Visuospatial processing in early Alzheimer's disease: a multimodal neuroimaging study", Cortex, Vol. 64, pp. 394-406.

Kazak, J., van Hoof, J., Świąder, M. and Szewrański, S. (2017), "Real estate for the ageing society - the perspective of a new market”, Real Estate Management and Valuation, Vol. 25 No. 4, pp. 13-24.

Kearns, W.D., Rosenberg, D., West, L. and Applegarth, S.P. (2009), "Attitudes and expectations of technologies to manage wandering behavior in persons with dementia”, Gerontechnology, Vol. 6 No. 2, pp. 89-101.

Kenigsberg, P.A., Aquino, J.P., Berard, A., Boucart, M., Bouccara, D., Brand, G., Charras, K., Garcia-Larrea, L., Gzil, F., Krolak-Salmon, P., Madjlessi, A., Malaquin-Pavan, É., Penicaud, L., Platel, H., Pozzo, T., Reintjens, C., Salmon, É., Vergnon, L. and Robert, P. (2015), "Les fonctions sensorielles et la maladie d'Alzheimer: une approche multidisciplinaire. [Sensory functions and Alzheimer's disease: a multi-disciplinary approach]", Gériatrie et Psychologie Neuropsychiatrie du Vieillissement, Vol. 13 No. 3, pp. 243-58 (in French). 
Kenigsberg, P.A., Aquino, J.P., Bérard, A., Brémond, F., Charras, K., Dening, T., Droës, R.M., Gzil, F., Hicks, B., Innes, A., Nguyen, M., Nygård, L., Pino, M., Sacco, G., Salmon, E., van der Roest, H., Villet, H., Villez, M., Robert, P. and Manera, V. (2017), "Assistive technologies to address capabilities of people with dementia: from research to practice", Dementia, 1 January, doi: 10.1177/1471301217714093.

Lawton, M.P. and Nahemow, L. (1973), "Ecology and the aging process", in Eisdorfer, L. and Lawton, M.P. (Eds), The Psychology of Adult Development and Aging, American Psychological Association, Washington, DC, pp. 619-74.

Luria, A.R. (1973), The Working Brain, Penguin Books, London.

Marquardt, G., Bueter, K. and Motzek, T. (2014), "Impact of the design of the built environment on people with dementia: an evidence-based review", Health Environments Research \& Design Journal, Vol. 8 No. 1, pp. 127-57.

Marshall, M. (1998), "Therapeutic buildings for people with dementia", in Judd, S., Marshall, M. and Phippen, P. (Eds), Design for Dementia, London, pp. 11-14.

Meares, R. (1999), "The contribution of hughlings jackson to an understanding of dissociation", American Journal of Psychiatry, Vol. 156 No. 12, pp. 1850-5.

Moretti, D.V. (2016), "Involvement of mirror neuron system in prodromal Alzheimer's disease", BBA Clinical, Vol. 5, pp. 46-53.

Motzek, T., Bueter, K. and Marquardt, G. (2017), "Investigation of eligible picture categories for use as environmental cues in dementia-sensitive environments", Health Environments Research \& Design Journal, Vol. 10 No. 4, pp. 64-73.

O’Callaghan, C., Bertoux, M., Irish, M., Shine, J.M., Wong, S., Spiliopoulos, L., Hodges, J.R. and Hornberger, M. (2016), "Fair play: social norm compliance failures in behavioural variant frontotemporal dementia", Brain, Vol. 139 No. Part 1, pp. 204-16.

Perry, B.D. (2002), "Neuroarcheology of childhood maltreatment. The neurodevelopmental costs of adverse childhood events", in Geffner, B. (Ed.), The Cost of Child Maltreatment: Who Pays? We all do, Haworth Press, New York, NY, pp. 61-88.

Perry, D.C., Datta, S., Sturm, V.E., Wood, K.A., Zakrzewski, J., Seeley, W.W., Miller, B.L., Kramer, J.H. and Rosen, H.J. (2017), "Reward deficits in behavioural variant frontotemporal dementia include insensitivity to negative stimuli”, Brain, Vol. 140 No. 12, pp. 3346-56.

Pezzati, R., Molteni, V., Bani, M., Settanta, C., Di Maggio, M.G., Villa, I., Poletti, B. and Ardito, R.B. (2014), "Can doll therapy preserve or promote attachment in people with cognitive, behavioral, and emotional problems? A pilot study in institutionalized patients with dementia", Frontiers in Psychology, Vol. 5, p. 342.

Phelps, E.A. and Anderson, A.K. (1997), "Emotional memory: what does the amygdala do?", Current Biology, Vol. 7 No. 5, pp. R311-R314.

Powers, W.T. (1973), Behaviour. The Control of Perception, Aldine de Gruyter, London.

Prince, M. and Jackson, J. (2009), "World Alzheimer report 2009". Alzheimer Disease International (ADI), London.

Pynoos, J., Cohen, E. and Lucas, C. (1989), "Environmental coping strategies for Alzheimer's caregivers", The American Journal of Alzheimer's Care and Related Disorders \& Research, Vol. 4 No. 6, pp. 4-8.

Ratey, J. (2003), A User's Guide to the Brain. Perception, Attention and the Four Theaters of the Brain, Pantheon, New York, NY.

Rijnaard, M.D., van Hoof, J., Janssen, B.M., Verbeek, H., Pocornie, W., Eijkelenboom, A., Beerens, H.C., Molony, S.L. and Wouters, E.J.M. (2016), "The factors influencing the sense of home in nursing homes: a systematic review from the perspective of residents", Journal of Aging Research.

Rizzolatti, G., Fabbri-Destro, M. and Cattaneo, L. (2009), "Mirror neurons and their clinical relevance", Nature Clinical Practice Neurology, Vol. 5 No. 1, pp. 24-34.

Rowe, J.W. and Kahn, R.L. (1997), "Succesful aging", The Gerontologist, Vol. 37 No. 4, pp. 433-40.

Seale, C. (Ed.) (2004), Researching Society and Culture, 2nd ed., Sage, London. 
Steeman, E., Godderis, J., Grypdonck, M., De Bal, N. and Dierckx de Casterlé, B. (2007), "Living with dementia from the perspective of older people: is it a positive story?", Aging \& Mental Health, Vol. 11 No. 2, pp. 119-30.

Ulrich, R.S. (2006), "Essay: evidence-based health-care architecture", The Lancet, Vol. 368 No. S1, pp. S38-9.

van der Plaats, A. and Verbraeck, B. (2008), De wondere wereld van dementie, Elsevier Gezondheidszorg, Maarssen (In Dutch).

van der Plaats, J.J. (2010), "Luria and Fozard as founders for creating suitable environments for people with dementia", Gerontechnology, Vol. 9 No. 3, pp. 380-7.

van Hoof, J. and Verkerk, M.J. (2013), "Developing an integrated design model incorporating technology philosophy for the design of healthcare environments: a case analysis of facilities for psychogeriatric and psychiatric care in The Netherlands", Technology in Society, Vol. 35 No. 1, pp. 1-13.

van Hoof, J., Kort, H.S.M. and van Waarde, H. (2009), "Housing and care for older adults with dementia. A European perspective", Journal of Housing and the Built Environment, Vol. 24 No. 3, pp. 369-90.

van Hoof, J., Blom, M.M., Post, H.N.A. and Bastein, W.L. (2013), "Designing a 'think-along dwelling' for people with dementia: a co-creation project between health care and the building services sector", Journal of Housing for the Elderly, Vol. 27 No. 3, pp. 299-332.

van Hoof, J., Kort, H.S.M., van Waarde, H. and Blom, M.M. (2010), "Environmental interventions and the design of homes for older adults with dementia: an overview", American Journal of Alzheimer's Disease and Other Dementias, Vol. 25 No. 3, pp. 202-32.

van Hoof, J., Kort, H.S.M., Duijnstee, M.S.H., Rutten, P.G.S. and Hensen, J.L.M. (2010), "The indoor environment and the integrated building design of homes for older people with dementia", Building and Environment, Vol. 45 No. 5, pp. 1244-61.

van Hoof, J., Rutten, P.G.S., Struck, C., Huisman, E.R.C.M. and Kort, H.S.M. (2015), "The integrated and evidence-based design of healthcare environments", Architectural Engineering and Design Management, Vol. 11 No. 4, pp. 243-63.

van Hooren, S.A., Valentijn, S.A., Bosma, H., Ponds, R.W., van Boxtel, M.P. and Jolles, J. (2005), "Relation between health status and cognitive functioning: a 6-year follow-up of the maastricht aging study", Journals of Gerontology Series B, Psychological Sciences And Social Science, Vol. 60 No. 1, pp. P57-P60.

Verkerk, M.J., Hoogland, J., van der Stoep, J. and de Vries, M.J. (2016), Philosophy of Technology - An Introduction for Technology and Business Students, Routledge, London.

Wachinger, C., Salat, D.H., Weiner, M. and Reuter, M. (2016), “Alzheimer's disease neuroimaging initiative. Whole-brain analysis reveals increased neuroanatomical asymmetries in dementia for hippocampus and amygdala", Brain, Vol. 139, pp. 3253-66.

Woods, R.T. (2001), "Discovering the person with Alzheimer's disease: cognitive, emotional and behavioural aspects”, Aging \& Mental Health, Vol. 5 No. S1, pp. S7-16.

Yin, R.K. (1994), Case Study Research - Design and Methods, 2nd ed., Sage, London.

Zamarian, L., Weiss, E.M. and Delazer, M. (2010), "The impact of mild cognitive impairment on decision making in two gambling tasks", Journal of Gerontology: Psychological Sciences, Vol. 66B No. 1, pp. 23-31.

Zuidema, S.U. (2008), "Neuropsychiatric Symptoms in Dutch nursing home patients with dementia", dissertation, Radboud University Nijmegen, Nijmegen.

\section{Authors affiliation}

Maarten J. Verkerk is based at the Department of Arts and Social Sciences of Maastricht University, Maastricht, The Netherlands.

Joost van Hoof is based at the Faculty of Social Work and Education, The Hague University of Applied Sciences, The Hague, The Netherlands, and at the Faculty of Environmental Engineering and Geodesy, Department of Spatial Economy, Wrocław University of Environmental and Life Sciences, Wroclaw, Poland. 
Sil Aarts is based at the Institute of Allied Health Professions, Fontys University of Applied Sciences, Eindhoven, The Netherlands.

Sylvia J.M.M. de Koning is based at the BreinCollectief - de Koning Creaties, Arnhem, The Netherlands.

Johanna J. van der Plaats is based at the BreinCollectief - van der Plaats Ouderenadvies, Riemst, Belgium.

\section{Corresponding author}

Joost van Hoof can be contacted at: jvhoof1980@hotmail.com; j.vanhoof@hhs.nl

For instructions on how to order reprints of this article, please visit our website: 